\title{
GÊNEROS TELEVISIVOS, REFERÊNCIA E ATUALIZAÇÃO: O JORNAL NACIONAL E O BALANÇO GERAL ES
}

\author{
Television genres, reference and upadate: Jornal Nacional and Balanço Geral \\ ES
}

Géneros televisivos, referencia e actualización: el Jornal Nacional y el Balanço Geral ES

Rafael Paes Henriques

Professor do Departamento de Comunicação Social da Ufes rafaelpaesh@gmail.com

\author{
Juliana Benichio Leite \\ Jornalista formada pela Ufes \\ benichiojuliana@gmail.com
}

\section{Resumo}

O objetivo deste artigo é investigar os modos de endereçamento de dois telejornais bastante distintos: o Jornal Nacional e o Balanço Geral ES. A ideia é identificar de que maneira esses produtos atualizam o subgênero telejornal, na medida em que repetem e reforçam aquilo que já está consolidado como sendo "o que se espera ver em um telejornal", ao mesmo tempo em que constroem um estilo próprio que os diferenciam dos demais telejornais, garantindo suas especificidades. Nosso corpus de análise é formado por 28 edições completas, o que equivale a duas semanas de exibição dos dois telejornais: do dia 17 ao dia 24 de outubro de 2015. Como resultado, identificamos algumas estratégias de enunciação desses produtos, que são efeitos de certas transformações pelas quais passa o telejornalismo na atualidade, e que também indicam algumas tendências e possíveis encaminhamentos desse subgênero no futuro.

Palavras-chave: Gêneros Televisivos. Modos de Endereçamento. Telejornalismo.

\begin{abstract}
This paper aims to investigate the modes of addressing of two very different news programs: Jornal Nacional and Balanço Geral ES. Our purpose is to identify how these products update the subgenre of the television newscast, as they repeat and reinforce what is already established as "what is expected to be seen on TV news", while building a unique style that set them apart from other news programs, thus establishing their specificities. Our corpus of analysis consists of 28 full editions, which is equivalent to two weeks of broadcast of both programs: from 17 to 24 October 2015. As a result, we identify some strategies of enunciation of these products, which are effects of certain transformations in which telejournalism passes
\end{abstract}


today, and which also indicate some tendencies and possible referrals of this subgenre in the future.

Key words: Television genres. Modes of Addressing. Television Newscast.

\section{Resumen}

El propósito de este artículo es investigar los modos de direccionamiento de dos telediarios muy diferentes: Jornal Nacional y Balanço Geral ES. Nuestro objetivo es identificar cómo estos productos actualizan el subgénero telediario a medida que repiten y refuerzan lo que ya está establecido como "lo que se espera que sea visto en el teleperiodismo", mientras que construyen un estilo único que los diferencian de otros programas de noticias, estableciendo así sus especificidades. Nuestro corpus de análisis consiste en 28 ediciones completas, lo cual es equivalente a dos semanas de emisión de ambos programas: de 17 a 24 de octubre de 2015 . Como resultado, identificamos algunas estrategias de enunciación de esos productos, que son efectos de ciertas transformaciones por las quales pasa el telediario en la actualidad, y que también indican algunas tendencias y posibles encaminamientos de ese subgénero en el futuro.

Palabras clave: Géneros televisivos. Modos de Direccionamiento. Teleperiodismo.

\section{INTRODUÇÃO}

O telejornalismo é uma atividade de destaque nas emissoras televisivas de sinal aberto do Brasil, estando historicamente presente. Trata-se, como o próprio nome já diz, da confluência entre a televisão, com seu amplo poder de difusão, e o jornalismo, com sua tarefa de informar sobre os acontecimentos da atualidade. Além de cumprirem com um papel social, os telejornais têm uma posição privilegiada na TV por também proporcionarem credibilidade às emissoras.

Assim como Gomes (2005, 2011a, 2011b, 2012), nossa abordagem sobre o telejornal classifica esse produto como sendo um subgênero, isto é, uma variação do gênero de programa jornalístico televisivo. Além de obedecer aos formatos e regras próprias do campo jornalístico e do campo televisivo, o telejornal deve ser analisado também como produto cultural. Sendo assim, em vez de algo cuja determinação já se encontra pronta e acabada, o telejornal constitui-se como: "um processo geral de permanente produção de sentido, que se dá nos processos de produção e consumo, nos processos de reconhecimento social do telejornalismo, no processo político de disputa sobre o que o telejornalismo pode ou deve ser" (GOMES, 2012, p. 40). 
Elizabeth Duarte e Vanessa Curvello (2009) afirmam que todo subgênero televisual possui um tom que lhe é adequado. O telejornal tem como tom a credibilidade, a singularidade dos fatos noticiados, a seriedade.

Entretanto, os produtos podem modificar tal tom, introduzindo novas combinatórias tonais que passam a fazer parte do programa, tornando-se suas marcas registradas, pois “[...] mesmo que não sejam sempre absolutamente originais, atuam como signo de diferenciação, com forte potencial fidelizador do público telespectador" (DUARTE e CURVELLO, 2009, p. 65). E o telejornalismo tem mesmo passado por significativas transformações ao longo do tempo. Trata-se de uma atividade que está em permanente atualização.

Sendo um produto cultural, o telejornal é transitório, instável, se transforma e assume diferentes formas e sentidos em cada momento histórico. Dessa forma, o objetivo deste artigo é justamente investigar os modos de endereçamento de dois telejornais bastante distintos: o Jornal Nacional (JN), da TV Globo e o Balanço Geral ES (BGES), da TV Vitória, afiliada Rede Record no Espírito Santo. A ideia é identificar de que maneira esses produtos atualizam o subgênero telejornal, na medida em que repetem e reforçam aquilo que já está consolidado como sendo "o que se espera ver em um telejornal", ao mesmo tempo em que constroem um estilo próprio que os diferenciam dos demais telejornais, garantindo suas especificidades. Dito em outras palavras, pretende-se identificar as marcas discursivas, certas características que constituem seus modos de endereçamento, ou seja, as maneiras pelas quais cada produto responde e dialoga com o que está historicamente definido como adequado ou inadequado a cada gênero ou subgênero discursivo.

O JN é o mais antigo programa televisivo ainda no ar na TV brasileira; foi o primeiro produto exibido em rede na história da televisão no país e, ainda hoje, é o telejornal com a maior audiência da TV aberta. Desse modo, é um produto que ainda constitui-se, como a maior referência para o subgênero telejornal no Brasil. O BGES é a versão capixaba de um formato aplicado pela Rede Record nas praças, em parceria com as emissoras afiliadas em diversas cidades brasileiras. Trata-se de um telejornal local exibido sempre no início da tarde, que, conforme pretendemos esclarecer, sempre dialoga com o JN, nem que seja para afirmar as suas diferenças. Com isso queremos indicar que, mesmo que se possa identificar, nesse produto, um modo particular, e bastante distinto do $\mathrm{JN}$, de atualizar o que é próprio ou impróprio para um telejornal, de um modo ou de outro, o BGES, e qualquer outro telejornal exibido no país, mantém invariavelmente algum grau de relação com o JN enquanto "modelo de referência" de telejornalismo no Brasil. 
Desse modo, a análise desses dois produtos pretende revelar as marcas que apontam, não somente para a forma mais "adequada" de se realizar um produto pertencente a esse subgênero, mas também, os "novos" modos de se fazer telejornal, isto é, as estratégias de enunciação que indicam as transformações do telejornalismo e a redefinição de suas fronteiras, de maneira que se possa identificar quais são as tendências e os possíveis encaminhamentos desse subgênero no futuro.

Para atingir esses objetivos, trabalharemos com os conceitos de gênero televisivo e modos de endereçamento como categorias de análise cultural, considerando aspectos ideológicos, sociais e culturais do telejornalismo.

O conceito de gênero televisivo permite dizer tanto do jornalismo como ideologia, valores, normas quanto das formas culturais historicamente dadas e, sobretudo, vincular nosso objeto de análise ao processo comunicacional gênero televisivo é uma estratégia de comunicabilidade (GOMES, 2011b, p. $18)$.

Nessa metodologia, busca-se articular as possíveis relações entre comunicação, sociedade, cultura e política, "através do conceito de gênero televisivo pensado como uma categoria cultural" (GOMES, 2012, p. 42). O gênero é um modo de situar os telespectadores em relação ao que se pode esperar de um programa, o que implica na sua forma, na escolha de seus assuntos e na maneira por meio da qual se comunica com seu público.

Os gêneros acionam mecanismos de percepção e de reconhecimento do popular; eles não são apenas qualidade dos textos, ou da narrativa, mas um mecanismo que funciona como dispositivo de leitura, de produção de sentido, de 'reencontro com o mundo' (MARTÍN-BARBERO, 2006a, p. 204) e são, por este motivo, o ponto de ancoragem da indústria midiática no aparato perceptivo das massas (GOMES, 2011a, p. 124).

Como forma de revelar os modos de endereçamento dos telejornais analisados, vamos utilizar os operadores de análise que vem sendo desenvolvidos e aplicados em diversas pesquisas realizadas pelo Grupo de Pesquisa em Análise de Telejornalismo (GPAT), da UFBA, coordenado pela professora Itânia Gomes: o mediador, o contexto comunicativo, o texto verbal, a organização temática e o pacto sobre o papel do jornalismo. Esses operadores são uma espécie de "lugares privilegiados" para onde o investigador deve olhar, já que podem servir como excelentes indicadores das maneiras e estratégias por meio das quais certo produto telejornalístico "põe em prática" o que está determinado pelo subgênero, construindo um modo de ser particular que não somente espelha ou reproduz o que é o padrão, como também pode pôr em prática certos deslocamentos capazes até de, a longo prazo, reconfigurar 
o que é próprio do subgênero ao qual pertence.

Através da articulação entre esses operadores, será possível identificar, então, quais são os atuais modos de endereçamento dos dois telejornais analisados, ou seja, como eles "se relaciona[m] com sua audiência a partir da construção de um estilo, que o[s] identifica[m] e que o[s] diferencia[m] dos demais" (GOMES, 2011b, p. 36).

A amostra empírica para este artigo inclui 28 edições completas, sendo duas semanas (do dia 17 a 24 de outubro de 2015) de cada um dos telejornais, de modo que seja possível realizar as comparações entre eles.

\section{OS MODOS DE ENDEREÇAMENTO DO BGES E JN}

A versão capixaba do Balanço Geral estreou no ano de 2009, com a apresentação do jornalista e radialista Amaro Neto. No momento de coleta dos dados, o BGES era transmitido pela TV Vitória, Rede Record, de segunda a sexta-feira das $12 \mathrm{~h} 30$ às 14h, e aos sábados, no horário especial das $12 \mathrm{~h}$ às $13 \mathrm{~h}$. O programa era dividido em 4 blocos, sendo que o primeiro apresenta apenas a cabeça de abertura de duas reportagens de destaque na edição.

O Jornal Nacional estreou no dia 1 de setembro de 1969 e, segundo o memorial da Globo no portal de notícias G11, "foi o primeiro telejornal do país a ser transmitido em rede nacional. Em pouco tempo, conquistou a preferência do público e se transformou num dos jornais mais respeitáveis da TV brasileira". O JN é transmitido pela Rede Globo, de segunda a sábado das $20 \mathrm{~h} 30$ às $21 \mathrm{~h} 15$, e dividido, em média, em 3 blocos. É apresentado por William Bonner e Renata Vasconcelos.

Ao longo dos últimos anos, o $\mathrm{JN}$ tem passado por significativas transformações. $\mathrm{O}$ BGES apresenta semelhanças e diferenças com algumas dessas mudanças, na medida em que também se atualiza. Grande parte dessas transformações se baseia na pretensão de construir e reconstruir - maior credibilidade e aproximação com os telespectadores de seus respectivos programas.

De acordo com informações do portal G12, o cenário do JN mudou muito ao longo dos seus quase 50 anos de existência. Nos primeiros anos, o cenário exibia, atrás dos apresentadores, o logotipo da TV Globo. Em 1972, o mapa mundi foi inserido ao lado da logomarca do telejornal; uma nova parede no cenário apareceu em 1979, e telas ao fundo com

$1 \mathrm{http} / / /$ memoriaglobo.globo.com/programas/jornalismo/telejornais/jornal-nacional/evolucao.htm

$2 \mathrm{http} / / /$ memoriaglobo.globo.com/programas/jornalismo/telejornais/jornal-nacional/redacao-como-cenario.htm 
exibição de imagens relacionadas às reportagens anunciadas pelo apresentador, foram inseridas em 1985.

A vinheta do telejornal com o logotipo, assim como o cenário móvel foram aprimorados com computação gráfica. $\mathrm{O}$ enquadramento também mudou: passou do close para o plano americano. Com o passar dos anos, o cenário ganhou características mais dinâmicas e mais possibilidades para a câmera passear no estúdio e explorar diferentes efeitos de luz.

Ainda segundo o site, foi a partir do ano 2000 que o estúdio passou a ser na redação. Quando a câmera não está à altura dos olhos dos apresentadores, a redação é revelada ao fundo, mostrando outros profissionais envolvidos na produção do programa. O cenário, então, ao mesmo tempo em que mostra a redação, expõe imagens gráficas que ilustram as reportagens. Em 2009, foi instalado um telão no estúdio, ao fundo, para essas ilustrações.

Durante a nossa análise, foi possível observar que, no ano de 2015, o JN trouxe mais transformações estéticas. Modernizou a bancada, de modo que o espaço se tornou mais amplo e claro para mobilidade dos apresentadores que agora não só transmitem notícias da bancada mas também em pé, por diversos ângulos. As conversas em tempo real com os correspondentes e equipes de reportagem estão mais interativas, através do telão no estúdio. As informações meteorológicas passaram a ser apresentadas ao vivo, direto da redação do JN, em São Paulo.

Essas últimas mudanças são as que mais aproximaram esteticamente o JN ao BGES, já que este último é apresentado de pé em um estúdio sem bancada. O BGES também foi modernizando o cenário com o tempo, sempre mantendo um espaço amplo e claro. A redação não aparece ao fundo, mas apenas nos momentos em que algum repórter apresenta notícias da redação, em tela dividida com Amaro. A vinheta do programa continua a mesma desde a sua estreia, e a diferença reside na abertura, que agora conta com uma música descontraída: "eu vou que vou, eu tô legal, na hora do almoço põe no Balanço Geral!", com a qual o apresentador canta e dança de forma cômica. Em seguida, após a chamada e o intervalo, Amaro volta no segundo bloco com funks criados por ele, que também passaram a marcar a abertura do telejornal. Um dos mais famosos é: “acabou câo, o Balanço começou, o Balanço começou!". Tudo isso tocando sempre uma buzina de gás, que simboliza o início do programa. "Toca a buzina que eu tô passando!".

Amaro, sempre em pé, circula livremente pelo estúdio. Como trata-se de um modelo de rede, que é replicado nas diversas praças, certas características do BGES também foram 
indicadas em trabalhos que analisaram o Balanço em outras localidades, como é o caso da investigação de Borja (2011), sobre o telejornal em Salvador, na Bahia. Segundo a autora, a performance do apresentador diante das câmeras "vem acompanhada de uma expansão do cenário, que ganha profundidade e arquitetura e uma maior variedade de movimentos de câmera" (BORJA, 2011, p. 230). É esse também o caso do BGES no qual o cenário também possui um telão de LCD por meio do qual Amaro se comunica com os repórteres.

\subsection{Mudanças na bancada}

Nos telejornais, cada mediador (âncoras, repórteres, comentaristas, correspondentes) estabelece um vínculo com o telespectador. Este, por sua vez, se acostuma com a presença diária/semanal dos mediadores, o que auxilia na construção da credibilidade dos profissionais e, consequentemente, do telejornal. O BGES conta com a participação de figuras bastante populares, como os repórteres Douglas Camargo, chamado de Camargão, e Vitor Moreno, identificado como Moreno ou Bailarino. O apresentador chama toda a equipe do telejornal por apelidos, como uma forma de demonstrar carinho e intimidade entre eles.

Amaro Neto é o mediador de destaque; é a partir de sua figura que o programa se estrutura. $\mathrm{O}$ apresentador guia o telejornal avaliando os fatos, intervindo nas cenas, atribuindo valores a determinados aspectos das reportagens, gerenciando o tempo, realizando as transições entre os segmentos do telejornal, escolhendo para qual câmera quer se dirigir, qual ângulo quer focar, enfim, se desdobra em diversos papéis. Em 2012, Amaro Neto deixou o programa e foi substituído por Fernando Fully, até sua volta ao BGES, em 2014.

Em todo o histórico do $\mathrm{JN}$, também houve várias trocas de apresentadores. Uma das mais memoráveis foi quando Cid Moreira e Sérgio Chapelin deixaram a bancada em abril de 1996, e, em seus lugares, assumiram os jornalistas William Bonner e Lillian Witte Fibe. "A substituição de Cid Moreira não significou apenas uma mudança na forma do telejornal, mas também em seu conteúdo" (PORTO, 2002, p. 20).

Segundo o portal G1, no tópico que aborda a evolução do programa3, a ideia, além de mudar o conceito de apresentação do Jornal Nacional, foi um reflexo da busca pela credibilidade no telejornalismo. A troca de locutores por jornalistas na apresentação das notícias foi uma estratégia da Globo para tornar o telejornal mais dinâmico. “O 'novo’ Jornal Nacional se caracteriza por um papel mais ativo e interpretativo dos apresentadores e por uma

3 http://memoriaglobo.globo.com/programas/jornalismo/telejornais/jornal-nacional/evolucao.htm 
cobertura mais plural" (PORTO, 2002, p. 20).

Quando Fátima Bernardes substituiu Lillian, por exemplo, foi também uma escolha estratégica, uma vez que o matrimônio de Fátima com Bonner era um fator que gerava identificação por parte das famílias que assistiam ao programa, que viam em um casal aparentemente feliz, uma imagem tradicional da família. "O exemplo de casal feliz, bonito e bem-sucedido é uma peça fundamental na composição do território limpo, discreto, quase asséptico do programa" (GOMES, 2005, p. 10).

\subsection{Tentativa de aproximação com os telespectadores}

A sociedade vai se transformando com o passar do tempo. A TV vai se modernizando, vão surgindo novas tecnologias, novos modelos de telejornais, os hábitos vão mudando e a concorrência entre as emissoras pela audiência vai aumentando. $\mathrm{O}$ estilo do $\mathrm{JN}$ em seus primeiros anos era mais:

[...] formal e engessado devido a diversos motivos: o surgimento no período de Ditadura Militar, quando havia muita censura sobre os veículos de comunicação; a busca pela credibilidade e pela construção de uma imagem confiável e transparente; o distanciamento dos apresentadores que, no princípio do telejornal, não participavam de todo o processo de produção do conteúdo noticiado, sendo apenas locutores (CARDOSO; CHINELATO e COUTINHO, 2013, p. 9)

Diante das inovações de outros telejornais, o JN passou também a modernizar seu estilo. No final dos anos 90, o JN passou a se preocupar em se aproximar mais dos telespectadores e com a compreensão do público em relação ao que era transmitido. Através de uma linguagem simples, passou a contextualizar e esclarecer as notícias. O telejornal, então, exigia uma atuação mais descontraída dos apresentadores, além de incorporar a participação de comentaristas especializados nos assuntos tratados.

No início, os apresentadores do $\mathrm{JN}$ : “[...] quase não falavam entre si e pouco se remetiam diretamente à audiência" (GOMES, 2012, p. 53). A opinião não explícita era uma estratégia para construir a imparcialidade do programa. Entretanto, a conduta dos apresentadores foi se alterando nos últimos anos, não modificando apenas seu texto verbal, como também sua performance.

Eles ainda permanecem sentados na bancada, com a redação ao fundo, no cenário familiar aos telespectadores do $\mathrm{JN},(.$.$) mas já protagonizam uma$ cena de tácita intimidade entre eles e, consequentemente, com o 
telespectador (GOMES, 2012, p. 52).

Atualmente, então, configura-se uma cena de maior informalidade e proximidade. Nas cabeças das reportagens, por exemplo, os apresentadores às vezes conversam entre si. Sandra Annenberg, que substituiu Renata Vasconcelos durante o período da análise, ao chamar uma reportagem sobre uma superpromoção em supermercados do Rio, diz: "Nesse momento, William, há outro tipo de garimpo, o de promoções (...)"4. Ou seja, ela apresenta a notícia aos apresentadores ao mesmo tempo em que parece conversar com Bonner.

Um outro exemplo de informalidade é o contato com a repórter Maria Júlia Coutinho, que informa a previsão do tempo. O apresentador levanta de sua bancada e fala diretamente com "Maju”, como é conhecida, através do telão. Na edição do dia 23 de outubro de 2015, por exemplo, William Bonner se dirige a Maju em tom descontraído, de conversa, para saber a previsão: "vamos ver então a previsão do tempo para este fim de semana de Enem. Quem vai fazer prova, quem tem filho que vai fazer prova do Enem, né Maju? Boa noite pra você, o que esse pessoal deve esperar do tempo?". No final, ao se despedir de Maju, ainda faz um comentário sobre a queda do nível dos rios na região Norte, depois de uma seca atípica: “situação difícil lá, tem criança até sem ter aula, né Maju?".

$\mathrm{Na}$ edição do dia 15 de outubro de 2015, após a exibição da reportagem sobre um engraxate que realizou o sonho de virar advogado em Goiás, William e Sandra também fazem comentários:

Sandra: Motivo de muito orgulho!

Bonner: Que história legal! É muito bom...

Sandra: Sensacional né? (olha para Bonner)

Bonner: A gente precisa dizer pro público que se todo dia o Jornal Nacional terminasse assim, nós também (faz gesto entre ele e Sandra) seríamos muito mais felizes.

Sandra: E orgulhosos de todos (sorri, olhando para Bonner e em seguida para a câmera).

Nesse diálogo, além da configuração de conversa entre os apresentadores, percebe-se que também se dirigem ao público. No JN, o telespectador é convidado a também fazer parte do contexto comunicativo por meio de expressões diretas, como "você" e "veja". Logo no início do programa é possível observar isso, ao fim da escalada da edição, os apresentadores afirmam: "você vai ver a partir de agora, no Jornal Nacional". Entretanto, vale ressaltar que a opinião dos apresentadores não é expressa somente nos comentários, uma vez que não é 
sempre que eles aparecem.

Os mediadores do Jornal Nacional exibem as notícias e esforçam-se para não comentá-las. Mas a expressividade que transmitem, tanto na entonação da voz quanto nas expressões faciais, os caracteriza como intérpretes da notícia (GOMES, 2005, p. 10).

No BGES, o texto verbal também se dirige diretamente aos telespectadores, porém de uma forma ainda mais íntima e informal. No início do programa, o apresentador sempre diz: "obrigado pelo carinho da sua audiência" e por diversas vezes tem a intenção de configurar um contexto comunicativo de conversa e intimidade com o telespectador. Um exemplo é a edição do dia 13 de outubro de 2015, em que Amaro pergunta: "como foi o feriadão prolongado? Maravilha? Dez a zero? Sensacional? Que bom! Vamos juntos com uma semana de muita informação e alegria aqui no nosso Balanço".

Amaro, inclusive, em todos os dias das edições analisadas, dedicou parte do tempo da programação para parabenizar aniversariantes e mandar beijos e abraços ao público. A performance de Amaro é essencial para estabelecer a aproximação com a audiência. É através da entonação de voz, do comportamento, dos gestos, das atitudes e da linguagem, que podem expressar alegria, revolta, humor, tristeza, seriedade, entre outros sentimentos, que o apresentador procura atrair a atenção do público.

Tudo é trabalhado de acordo com o apelo emocional, e uma mesma reportagem pode se estender por longo tempo à medida em que seus acontecimentos são descritos e comentados detalhadamente por Amaro. A forma de trabalhar e transmitir as notícias no BGES tem como objetivo provocar sensações no público. O telejornal noticia os fatos sempre destacando os aspectos de curiosidade, do extraordinário, do choque e da dramatização. Estratégia também identificada por Escosteguy (2012) no programa Brasileiros, exibido pela TV Globo, em 2010.

A narração dos relatos de vida de cada um desses indivíduos, voltada mais para um apelo sentimental do que para um caráter meramente informativo e descritivo, é mais um elemento que efetiva a comunicação, isto é, o compartilhamento de experiências pessoais instala uma relação emocional entre telespectador e programa jornalístico (ESCOSTEGUY, 2012, p. 32).

Vários elementos contribuem para despertar as emoções do público do BGES em relação a uma notícia, que vão desde a trilha sonora até os movimentos das câmeras, a fala dos repórteres e as reações de Amaro. Um exemplo é a reportagem exibida no dia 23 de outubro de 2015, que mostra o caso de um jovem que morreu em um acidente dentro da empresa em que trabalhava. A reportagem começou mostrando a chegada dos parentes da 
vítima desesperados ao local do acidente; inclusive exibiu o momento em que o pai chora e grita inconformado com a morte do filho. Uma senhora que testemunhou o acidente deu seu depoimento emocionada. O repórter relatou o que aconteceu e, em seguida, acrescentou informações sobre o jovem, enquanto as fotos dele eram exibidas.

Depois, a reportagem expõe mensagens de amigos que lamentam a morte em uma rede social da vítima. Em uma segunda matéria sobre o caso, foi exibida uma entrevista com o tio do jovem, que diz que ele era muito querido, alegre e que estava feliz com o novo emprego que conseguira havia pouco tempo. O tio ainda lembra das últimas palavras do jovem para a mãe antes de sair para o trabalho, quando disse que a amava. É uma reportagem que apela para a sensibilidade do telespectador ao mostrar os detalhes do caso de um jovem que teve a vida interrompida muito cedo por uma fatalidade no trabalho, destacando o quanto ele era uma pessoa querida e o quanto os familiares e amigos lamentaram sua perda.

Um outro exemplo foi uma reportagem da edição do dia 16 de outubro de 2015, que contou um caso em que traficantes invadiram, incendiaram uma casa e atiraram na família. A matéria começou com a repórter mostrando como a casa ficou após o ocorrido e contando o que aconteceu. Entre as vítimas estava uma adolescente de 14 anos e sua mãe. Testemunhas contam o que presenciaram e o proprietário da casa, que era alugada pela família, relata que não tinha problemas com a inquilina e se emociona com a destruição de seu patrimônio, que precisou de muitos anos para construir. Nos comentários, Amaro lamenta o ocorrido, principalmente pelo proprietário: "Você pode acompanhar aquele senhor, triste porque ele construiu no peito e na raça essa casa, alugou pra esse pessoal há um ano e acontece isso". Amaro também pede para os telespectadores denunciarem caso saibam de alguma coisa. "Se você puder nos ajudar, se você tiver a condição de ajudar a gente e a polícia nas investigações: ligue". Trata-se de uma reportagem que tem por objetivo despertar o sentimento de indignação no telespectador.

Uma outra estratégia do programa é o uso da linguagem coloquial, e até de expressões populares principalmente no texto verbal de Amaro, que deixa o ambiente bem informal e descontraído. Como exemplo encontrado na nossa amostra, podemos destacar a edição do dia 19 de outubro de 2015, em que o apresentador utilizou das seguintes expressões: "O rato trepado dentro do busão já chegando desse jeito, tocando o terror pra cima de todo mundo". "Um simpático foi rasgado na Serra. Tomou um pipoco". "Você viu essa treta doida?". Tratase de uma forma de indicar que Amaro está "ao lado do povo" ao "falar como o povo", de mostrar que o apresentador, e, assim, o programa, funcionam como porta-voz da população. 
Além disso, Amaro sempre mantém uma postura didática ao transmitir as notícias, repetindo as informações já presentes na reportagem que acabou de ser exibida. As informações são "traduzidas" para melhor entendimento do telespectador. Ele conduz o programa guiando a audiência, chamando atenção para determinados aspectos e os explicando.

No JN, o didatismo se encontra na confirmação de todas as informações por dados, números e porcentagens. "O uso do recurso da 'arte' para ilustrar mapas, gráficos e tabelas é outra constante, que caracteriza certo didatismo do programa" (GOMES, 2005, p. 8). Na amostra deste artigo, tais dados estatísticos e ilustrações estão presentes não somente durante as reportagens, como também na nota pé dos apresentadores.

No que diz respeito aos dispositivos utilizados para configurar um contexto comunicativo de proximidade entre mediadores e telespectadores, temos, além do texto verbal, os enquadramentos de câmera. No JN,

\begin{abstract}
Além do enquadramento padrão do telejornal, da câmera parada na altura da bancada, recorre-se ao travelling que sai do close no mediador e se distancia de modo vagaroso até o plano americano, enquanto a cabeça do VT é proferida, movimento que desenha o percurso do olhar do telespectador que se aproxima e se afasta dos apresentadores (GOMES, 2012, p. 53).
\end{abstract}

Atualmente, os apresentadores introduzem as notícias, olhando de frente para a câmera e, em alguns casos, viram a cadeira e olham para uma outra câmera, que mostra um outro ângulo do apresentador, visto mais de cima.

Enquanto isso, no BGES, Amaro procura indicar que é ele quem determina qual ângulo a câmera vai focar. Ele sempre está dirigindo comandos ao cinegrafista chamado de "italiano". Quando diz, por exemplo, para o telespectador "chegar mais", a câmera, propositalmente, dá um close na imagem de Amaro.

Enquanto buscam aproximação com o público, os telejornais também procuram construir sua credibilidade. No JN, uma das formas mais notáveis está no desenvolvimento dos dois lados da notícia, ou seja, não se procura mostrar apenas um ponto de vista da reportagem, mas sim a perspectiva tanto de quem exerce quanto de quem sofre a ação. "Isso se faz pelo recurso da valorização da sua cobertura jornalística, que mostra ao telespectador a fonte das notícias, e do destaque ao trabalho dos repórteres" (GOMES, 2012, p. 50). A observação de Gomes sobre o JN também se aplica ao BGES, já que, em suas reportagens que denunciam determinado crime ocorrido no estado, "o lado negativo é mostrado em imagens de câmera escondida, enquanto as vítimas e as fontes oficiais aparecem nas sonoras, espaço 
reservado para as entrevistas" (GOMES, 2005, p. 7).

A categorização das fontes de informação presentes na amostra dos dois telejornais indica justamente a distribuição da presença dos envolvidos com as notícias. No Gráfico 1, apresentamos o resultado do levantamento da classificação das fontes presentes no Jornal Nacional (TV Globo) e no Gráfico 2, os dados referentes ao levantamento dos tipos de fontes presentes no Balanço Geral ES (TV Vitória), no período analisado.

Gráfico 1: Presença de fontes no Jornal Nacional (JN).

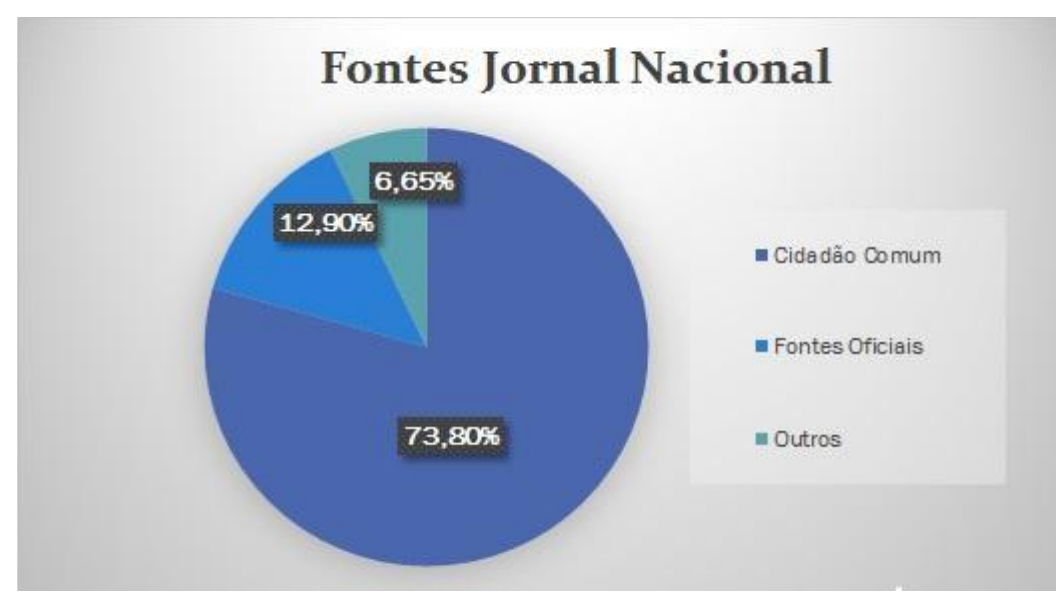

Fonte: Levantamento realizado para este trabalho.

Gráfico 2: Presença de fontes no Balanço Geral ES (BGES).

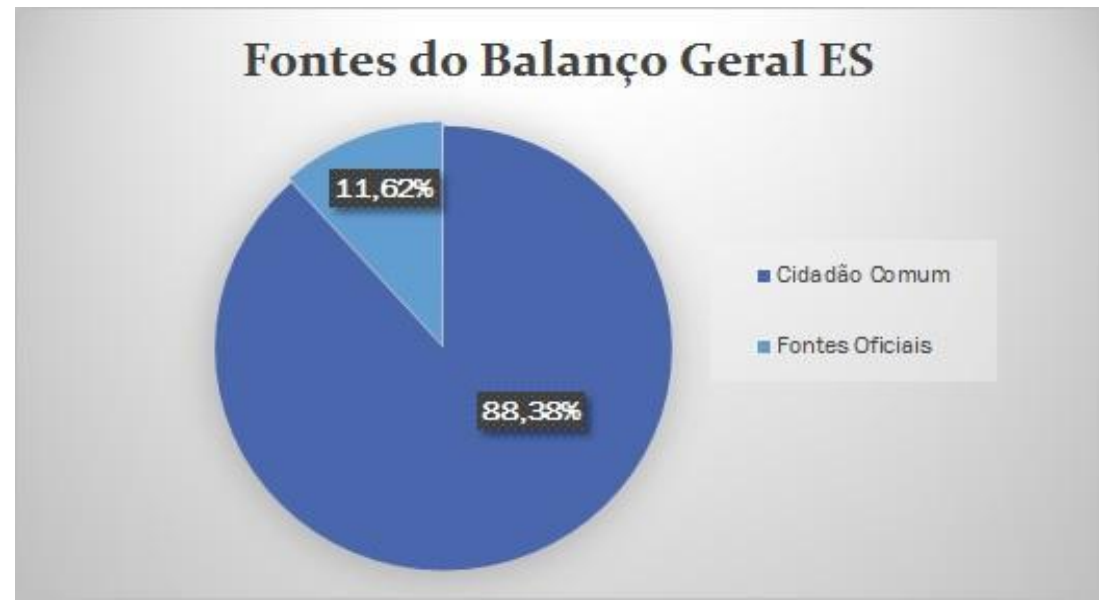

Fonte: Levantamento realizado para este trabalho.

Do total de 496 fontes (100\%) do JN, 366 (73,80\%) são cidadãos comuns, 97 $(12,90 \%)$ são fontes oficiais (funcionários públicos, membros dos poderes legislativo, judiciário e executivo) e $33(6,65 \%)$ são outras fontes - como artistas, por exemplo. Já no BGES, do total de 198 fontes (100\%), 175 (88,38\%) são cidadãos comuns e $23(11,62 \%)$ são 
fontes oficiais. Conclui-se que os dois telejornais têm como prioridade dar voz aos cidadãos comuns.

No que diz respeito à valorização da cobertura jornalística, tanto a estrutura do JN quanto a estrutura do BGES mantêm o clássico formato de apresentação da notícia: chamada, off, passagem e sonoras. O "ao vivo" também está presente nos telejornais, embora não seja em todas as edições. Das 14 edições analisadas do BGES, apenas 4 edições 5 continham entradas 'ao vivo', enquanto que nas 14 edições do JN, apenas 2 edições 6 exibiram formato jornalístico dessa natureza. No caso do JN, após a exibição da reportagem, há quase sempre a nota pé; enquanto que no BGES são realizados longos comentários de Amaro. As duas tabelas a seguir indicam a quantidade de offs, sonoras e passagens nas reportagens de cada telejornal, assim como o tempo (em segundos) dedicado a cada um desses elementos da reportagem.

Tabela 1: Distribuição do tempo na reportagem do Jornal Nacional (JN).

\begin{tabular}{|c|c|c|}
\hline Elemento da reportagem & Quantidade & Tempo (s) \\
\hline Off & 646 & 12.279 \\
\hline Sonora & 603 & 5893 \\
\hline Passagem & 152 & 3993 \\
\hline Nota pé & 76 & 1007 \\
\hline
\end{tabular}

Fonte: Levantamento realizado para este trabalho.

Tabela 2: Distribuição do tempo na reportagem do Balanço Geral ES (BGES).

\begin{tabular}{|c|c|c|}
\hline Elemento da reportagem & Quantidade & Tempo (s) \\
\hline Off & 309 & 5076 \\
\hline Sonora & 324 & 5527 \\
\hline Passagem & 97 & 2228 \\
\hline
\end{tabular}

Fonte: Levantamento realizado para este trabalho.

Na tabela 1, do JN, observa-se que a quantidade e o tempo de offs é maior que os outros elementos da reportagem, enquanto que na tabela 2, do BGES, a quantidade e o tempo de sonoras é maior. Podemos indicar que o JN constrói sua credibilidade dando mais voz ao repórter (off e passagem) enquanto que o BGES dá voz às fontes (sonoras). A nota pé é bastante utilizada no JN. Elas servem para, além de complementar a reportagem, “[...] demonstrar que outras fontes foram acessadas [...]; para explicitar um determinado julgamento [...]; ou como forma de retificar um erro cometido pelo programa" (GUTMANN,

5 Edições dos dias 16/10/2015 (sexta-feira), 17/10/15 (sábado), 23/10/15 (sexta-feira) e 24/10/15 (sábado).

6 Edições dos dias 12/10/15 (segunda-feira) e 21/10/15 (quarta-feira). 
2009, p. 12).

Além do esforço de realizar uma aproximação com o público, os telejornais analisados neste artigo também não deixam de dispor de algumas estratégias discursivas de distanciamento. Esse duplo posicionamento do apresentador, que ao mesmo tempo em que está "ao lado do povo", tem acesso privilegiado às autoridades, também foi observado por Borja (2011), em sua análise do Balanço Geral de Salvador, Bahia. O lugar de destaque do jornalista: "[...] o autoriza a selecionar, classificar e valorar os acontecimentos do mundo" (BORJA, 2011, p. 232).

A postura supostamente didática de Amaro após as reportagens é um exemplo, pois ao comentar a matéria, o apresentador explica e repete os fatos para melhor entendimento do público e, assim, assegurar proximidade com os telespectadores. Amaro também expõe suas opiniões e, em alguns casos, faz apelos de melhorias às autoridades (prefeitura, polícia, etc.), exercendo, então, seu papel de apresentador e de intermediário entre o poder público e o público espectador. Ele reforça sua autoridade ao dar a última palavra.

No caso do JN, as notas pé também servem como estratégia de distanciamento, pois é o apresentador quem dá a última palavra. A matéria é complementada com informações adicionais ou até mesmo com comentários dos apresentadores sobre o assunto noticiado.

\subsection{Pacto sobre o papel do jornalismo}

O principal pacto estabelecido com a audiência no JN é o de servir como fonte de resumo diário do que é importante no cotidiano do país e do mundo. Na verdade, do país que é privilegiado pelo noticiário, visto que alguns Estados são muito mais noticiados do que outros. No nosso período de análise, do total de 246 reportagens (100\%), 36 são referentes a fatos que aconteceram em São Paulo (14,63\%), 33 no Rio de Janeiro (13,41\%) e 31 em Brasília (12,60\%), o que, somado, já equivale à 40,64\% do telejornal. Todo restante são reportagens sobre acontecimentos que ocorreram em outros Estados ou no exterior.

No JN, "a capacidade de 'estar lá' é construída a partir da exploração de correspondentes e da exploração das entradas ao vivo" (GOMES, 2012, p. 50). Trata-se de uma maneira não somente de construir e assegurar sua credibilidade, como também o seu pacto sobre o papel do jornalismo.

O Jornal Nacional foi pioneiro em enviar correspondentes para outros países, a fim de cobrir notícias internacionais. $\mathrm{O}$ "estar ali”, a presença do repórter, assegura a credibilidade à narração do fato e, em longo prazo, ao jornal que 
o anuncia (GOMES, 2005, p. 9).

Os apresentadores valorizam esse trabalho dos repórteres e sempre dizem seus nomes na abertura das matérias. Na edição do dia 23 de outubro de 2015, Sandra Annenberg, ao falar sobre um furacão que seria um dos mais fortes da história do Ocidente, conversa ao vivo com a correspondente no telão: "por isso a gente vai agora conversar com a nossa correspondente lá em Nova Iorque, Sandra Coutinho, que está acompanhando tudo”. Outro exemplo é o da edição do dia 22 de outubro de 2015, na reportagem sobre a situação das contas do governo e sua relação com a inflação, quando Bonner diz: "a gente vê na reportagem do José Roberto Burnier". Ou na edição do dia 16 de outubro de 2015, quando Sandra diz: “a reportagem é da Camila Bonfim". Trata-se de uma estratégia que "legitima a fala do repórter que está no local do acontecimento" (GOMES, 2005, p. 7).

O JN também tem por objetivo sustentar a conversação social, ou seja, apresentar “[...] o grande resumo das principais notícias do dia [...] apenas o essencial de cada uma das editorias é suficiente para repor o estoque de informação para a conversa do próximo dia" (GOMES, 2005, p. 8). Ou seja, também organiza e seleciona o que tem de mais importante no fluxo de informações de cada edição.

O pacto do BGES defende discursivamente a ideia de um jornalismo de vigilância. O programa quer garantir que está sempre atento aos acontecimentos da sociedade, realizando denúncias e procurando soluções. O telejornal classifica o telespectador como um indivíduo que não tem voz no ponto de vista discursivo, a não ser no próprio telejornal. Ao dar voz às comunidades, transmitir seus problemas do dia-a-dia, ao se colocar ao lado do povo, agindo como seu defensor, ou seja, ao representar o povo, o programa fortalece seu pacto com a audiência.

No programa, algumas reportagens noticiam os crimes flagrados por imagens das câmeras de videomonitoramento de pontos comerciais, bancos, entre outros lugares. É como se essas câmeras representassem "os olhos" do telejornal e suas imagens atentassem a credibilidade dos fatos. Como que para enfatizar isso, as imagens são sempre repetidas nas matérias, principalmente para cobrir a fala de Amaro.

Outro aspecto dentro do BGES que estabelece o pacto com a audiência é o quadro "Praça do Povo". Nesse quadro, a equipe do programa vai às praças e oferece oportunidade para as pessoas darem o seu recado, fazendo pedidos de ajuda com seus problemas pessoais, denúncias, reclamações e expondo suas opiniões. 


\subsection{Organização Temática}

No período analisado por este trabalho, o BGES exibiu 152 reportagens e o JN 246. Os gráficos a seguir representam a organização temática dos telejornais, indicando a porcentagem de cada uma de suas editorias.

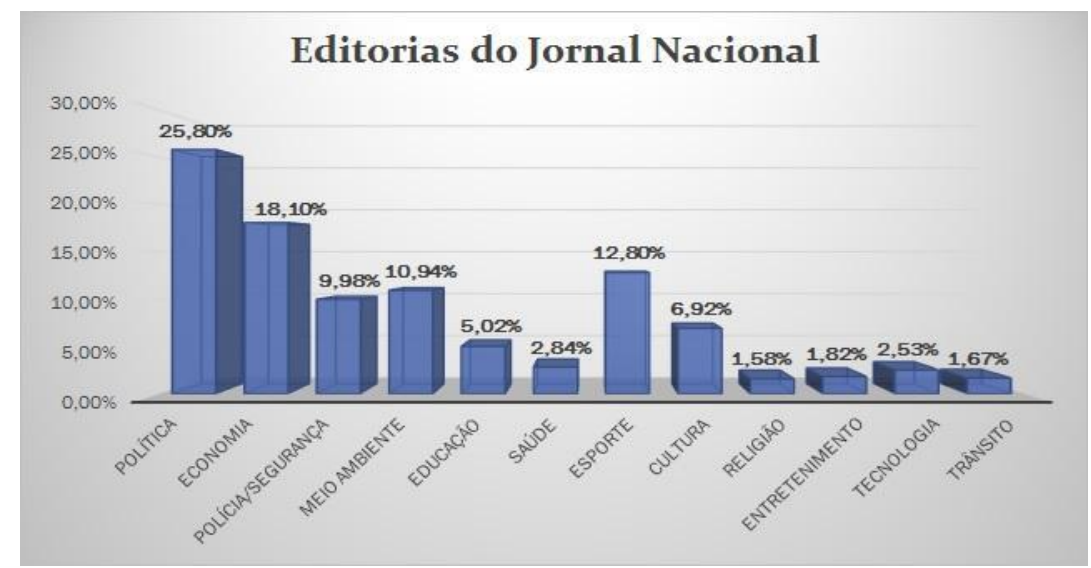

Gráfico 3: Divisão por editorias no Jornal Nacional (JN).

Fonte: Levantamento realizado para este trabalho

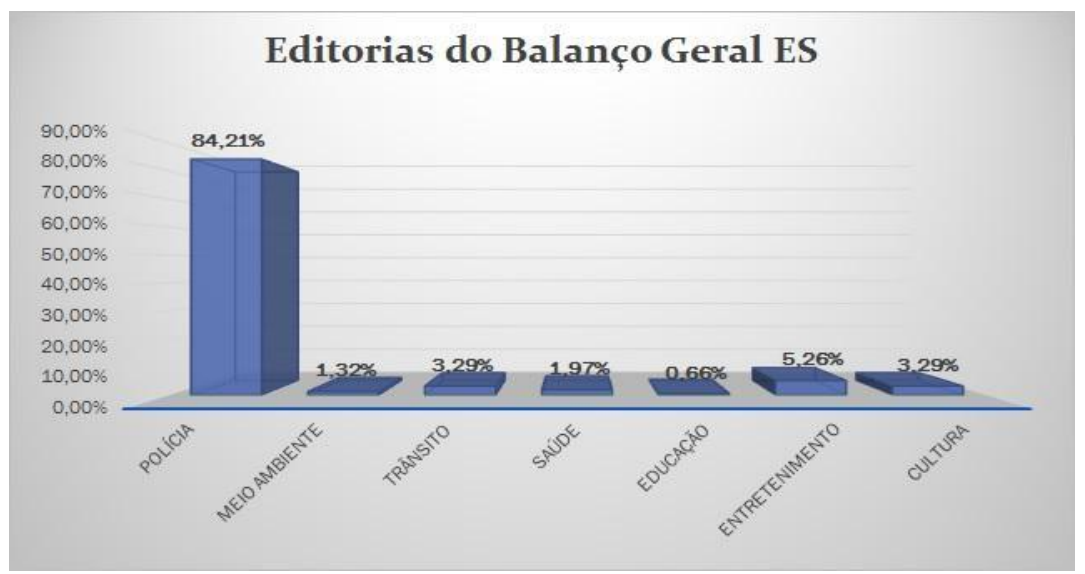

Gráfico 4: Divisão por editorias no Balanço Geral ES (BGES).

Fonte: Levantamento realizado para este trabalho.

Como é possível observar no gráfico 3, as 246 reportagens (100\%) analisadas do JN foram divididas em 12 categorias: Política (Nacional e Internacional), Economia, Polícia, Meio Ambiente, Educação, Saúde, Esporte, Cultura, Religião, Entretenimento, Tecnologia e Trânsito. A categoria de Política está em primeiro lugar no programa, com 25,80\% do total. Em segunda lugar, vem Economia com 18,10\%, e em terceiro, Esporte com 12,80\%. Por último está a categoria de Religião, com 1,58\%. 
No gráfico 4 estão as editorias das 152 reportagens (100\%) do BGES, classificadas em: Polícia, Meio Ambiente, Trânsito, Saúde, Educação, Entretenimento e Cultura. A diferença é significativa. A categoria predominante é a de Polícia, que ocupa 84,21\% do total, enquanto que as outras categorias se mantém em porcentagens pequenas. Em segundo lugar está Entretenimento, com 5,26\%, e por último Educação, com 0,66\%.

A organização temática desses telejornais é bem definida, pois geralmente começa do fato mais "forte" e termina nos assuntos mais "leves", conforme já identificado por Gomes (2005) em trabalho anterior: "No JN, esse movimento é percebido tanto no jornal como um todo, quanto entre os blocos" (GOMES, 2005, p. 9).

No período de análise para este artigo, o JN apresentou mais notícias de Política. Porém a diferença com as outras categorias não é tão significativa, já que o programa apresenta uma linha editorial com mais variedades de categorias temáticas em relação ao BGES. Mesmo resultado encontrado anteriormente: "O Jornal Nacional não parece manter uma 'paginação' muito fixa, mas mantém alguns parâmetros que se tornaram referência para o próprio gênero" (GOMES, 2005, p. 9).

No BGES, é a categoria de Polícia que predomina, o que nos permite concluir que se trata de um telejornal de temática policial. É dividido em 4 blocos, sendo o primeiro apenas a chamada dos destaques. O segundo bloco tem $1 \mathrm{~h}$ de duração, no qual as notícias são transmitidas sem intervalo. Os fatos mais "fortes" são noticiados nesse bloco, enquanto os outros três se dividem na transmissão dos assuntos mais "leves", como os anúncios publicitários e o quadro "Praça do Povo".

O BGES é um veículo que divulga os produtos e serviços de seus patrocinadores. A publicidade divide espaço com o noticiário, variando numa média de 4 a 10 anúncios por programa. Isso acaba prejudicando o conteúdo jornalístico do telejornal. Tanto que meia hora de programação do JN contém mais reportagens do que 1 h30 do BGES, como foi possível observar na amostra, que equivale a duas semanas de análise para cada telejornal.

\section{CONSIDERAÇÕES}

Tanto o JN quanto o BGES passaram, ao longo do tempo, por uma série de mudanças. Essas transformações acompanharam as inovações tecnológicas e os momentos históricos. O telejornal precisa conquistar e reconquistar a fidelidade da audiência em cada edição e para isso "adota um leque de estratégias comunicativas que se movem em maior ou menor grau ao 
longo do tempo, acompanhando e também determinando o fluxo de mudanças no contexto onde está inserido" (GOMES, 2012, p. 54).

A princípio, o JN adotava uma postura mais séria e distante do telespectador, pois acreditava estar construindo imparcialidade e passando mais veracidade aos fatos veiculados. Porém, com as mudanças da sociedade e com os telejornais concorrentes aderindo às mudanças, o JN se viu obrigado a se modernizar.

A aproximação com o público é, portanto, importante para a permanência do telejornal. Sendo assim, o programa se tornou mais flexível e dinâmico, os apresentadores passaram a interagir mais entre si e com os telespectadores. O BGES também busca essa aproximação. Pode ser definido como um telejornal que sintetiza um caráter popular quando tem como objetivo retratar o cotidiano do povo, estabelecendo uma relação de aproximação através de recursos de linguagem, imagens e sons voltados ao apelo emocional. Procura-se desenvolver um processo de identificação dos telespectadores para com o programa com a finalidade de captar sua fidelidade, de garantir audiência.

O JN pode ser considerado um telejornal que se constitui como uma certa “estabilidade em fluxo”, ou seja, suas características são referências no Brasil do que é um telejornal, isto é, suas particularidades se confundem com as marcas do subgênero telejornal; ao mesmo tempo em que é um produto da sociedade e da cultura e, por isso, está em constante transição nos diferentes momentos históricos. O BGES também atualiza o gênero programa jornalístico televisivo, ou seja, acompanha as transformações do JN - uma vez que este é um telejornal de referência. Entretanto, não deixa de construir seu estilo próprio, que o diferencia dos demais telejornais. O JN e o BGES atualizam o gênero telejornal, ao mesmo tempo, e na medida em que estruturam seus próprios modos de endereçamento.

\section{REFERÊNCIAS}

BORJA, Janira. O grito da cidade: Balanço Geral, qualidade e modos de endereçamento. In: GOMES, Itânia Maria Mota. (Org.). Gêneros televisivos e modos de endereçamento no telejornalismo. Salvador: EDUFBA, 2011, p. 224-242.

BOURDIEU, Pierre. Sobre a televisão. Rio de Janeiro: Jorge Zahar Ed., 1997.

CARDOSO, Letycia Moreira; CHINELATO, Sabrina Henriques; COUTINHO, Iluska Maria da Silva. As mudanças na bancada do Jornal Nacional. ENCONTRO NACIONAL DE HISTÓRIA DA MÍDIA, 9., 2013, Juiz de Fora. Anais eletrônicos... Disponível em <http://www.ufrgs.br/alcar/encontrosnacionais-1/9o-encontro-2013/artigos/gt-historia-do-jornalismo/as-mudancas-na-bancada-do-jornal- 
nacional>. Acesso em 12 out. 2015.

DUARTE, Elizabeth Bastos; CURVELLO, Vanessa. Telejornais: quem dá o tom?. In: GOMES, Itania Maria Mota. (Org.). Televisão e realidade. Salvador: EDUFBA, 2011, p. 61-74.

ESCOSTEGUY, Ana Carolina D. Jornalismo e estudos culturais: uma perspectiva cultural. In: GOMES, Itania Maria Mota. (Org.). Análise de telejornalismo: desafios teórico-metodológicos. Salvador: EDUFBA, 2012, p. 25-38.

GOMES, Itânia Maria Mota. (Org.). Estabilidade em fluxo: uma análise cultural do Jornal Nacional, da Rede Globo. In: (org.). Análise de telejornalismo: desafios teórico-metodológicos. Salvador: EDUFBA, 2012, p.39-58.

Gênero televisivo como categoria cultural: um lugar no centro do mapa das mediações de Jesús Martín-Barbero. Revista FAMECOS, Porto Alegre, v.18, n.1, p.111-130, 2011a. (Org.). Metodologia de análise de telejornalismo. In: Gêneros televisivos e modos de endereçamento no telejornalismo. Salvador: EDUFBA, 2011b, p. 18-47.

Modo de endereçamento no telejornalismo do horário nobre brasileiro: o Jornal Nacional, da Rede Globo de Televisão. In. CONGRESSO BRASILEIRO DE CIÊNCIAS DA COMUNICAÇÃO, 28., 2005, Rio de Janeiro. Anais eletrônicos... Disponível em <http://www.portcom.intercom.org.br/pdfs/74277217742772103772621605140235486090.pdf>. Acesso em 12 out. 2015.

GUTMANN, Juliana Freire. Articulações entre dispositivos televisivos e valores jornalísticos na cena de apresentação do Jornal Nacional. In. CONGRESSO BRASILEIRO DE CIÊNCIAS DA COMUNICAÇÃO, 32., 2009, Curitiba. Anais eletrônicos... Disponível em <http://intercom.org.br/premios/2009/Gutmann.pdf >. Acesso em 12 out. 2015.

MARTÍN-BARBERO, Jesús. Dos meios às mediações. Comunicação, Cultura e Hegemonia. Rio de Janeiro: Ed. UFRJ, 2006.

PORTO, Mauro P. Novos apresentadores ou novo jornalismo? O Jornal Nacional antes e depois da saída de Cid Moreira. Comunicação e Espaço Público, Brasília, v. 5, n. 1/2, p. 9-31, 2002. 


\section{Rafael Paes Henriques}

É professor adjunto do Departamento Comunicação Social da Universidade Federal do Espírito Santo

(Ufes), desde 2012. Possui graduação em Comunicação Social/Jornalismo pela Ufes (2003), graduação em Filosofia pela Ufes (2012), mestrado em Ciências da Comunicação pela Universidade do Minho (2008) e doutorado em Filosofia pela Universidade Federal do Rio de Janeiro (UFRJ) (2012). É professor permanente do Programa de Pós-Graduação em Comunicação e Territorialidades e do Programa de Pós-Graduação em Filosofia, ambos da Ufes.

Juliana Benichio Leite

É graduada em Comunicação Social/Jornalismo pela Universidade Federal do Espírito Santo (Ufes) (2017), onde foi bolsista de Iniciação Científica (IC).

Esta obra está licenciada sob uma Licença Creative Commons.

Esta obra está licenciada sob uma Licença Creative Commons. 